\title{
Primary mural infective endocarditis with associated central line infection
}

\author{
Yashwant Agrawal, ${ }^{1}$ Rachel Dada, ${ }^{2}$ Jafar Dada, ${ }^{2}$ Michelle Degregorio ${ }^{2}$
}

${ }^{1}$ Cardiology, St. Joseph Mercy Oakland Hospital, Pontiac, Michigan, USA

${ }^{2}$ St. Joseph Mercy Oakland Hospital, Pontiac, Michigan, USA

\section{Correspondence to}

Yashwant Agrawal, yashwantagrawal.agrawal@ gmail.com

Accepted 17 October 2018

\section{DESCRIPTION}

A 60-year-old woman presented to the emergency room with altered mental status. Three weeks prior, a right-sided central venous access port was inserted for antibiotic administration for a recurrent urinary tract infection (UTI). Since the procedure, she had aching right-sided shoulder pain, lethargy, fever, chills, vomiting, weight loss, cough and sore throat. Vitals were significant for tachycardia of $144 \mathrm{bpm}$ and tachypnoea with 24 breaths per minute. Physical examination was unremarkable. Laboratories were significant for leucocytosis of $20 \times 10^{9} / \mathrm{L}$, lactic acid $13.9 \mathrm{mmol} / \mathrm{L}$, blood urea nitrogen (BUN) $44 \mathrm{mg} / \mathrm{dL}$, creatinine $2.03 \mathrm{mg} / \mathrm{dL}$, glomerular filtration rate (GFR) $25 \mathrm{~mL} / \mathrm{min} / 1.73 \mathrm{~m}^{2}$, and urinalysis showed signs of infection.

ECG revealed sinus rhythm with premature atrial complexes and paroxysms of atrial fibrillation. Chest X-ray revealed the central venous access port tip at the cavoatrial junction. Transthoracic echocardiogram (TTE) revealed ejection fraction (EF)

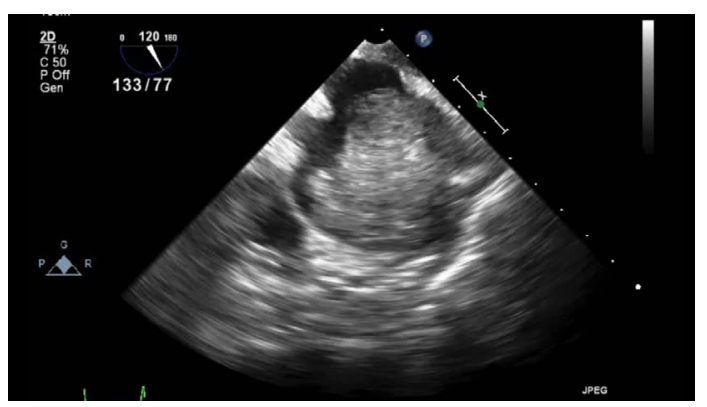

Video 1 Transthoracic echocardiogram four-chamber view depicting difficult visualisation of the right atrial mass. 2D, two dimensional.

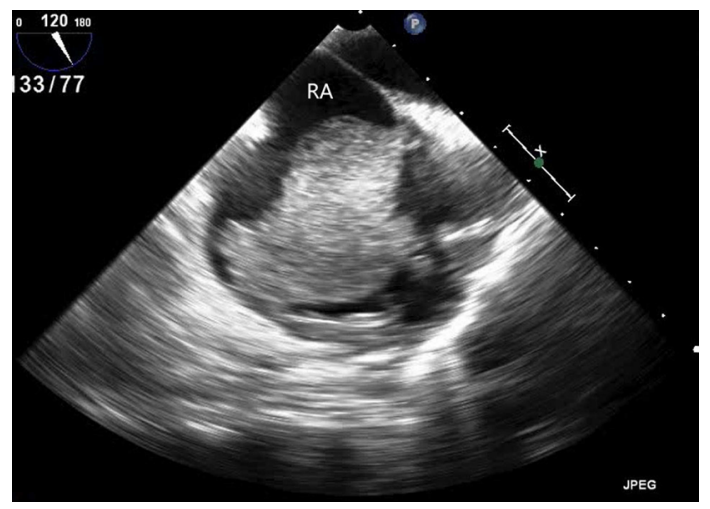

Figure 1 Transoesophageal echocardiogram visualising the vegetation within the right atrium attached to the interatrial septum. RA, right atrial.

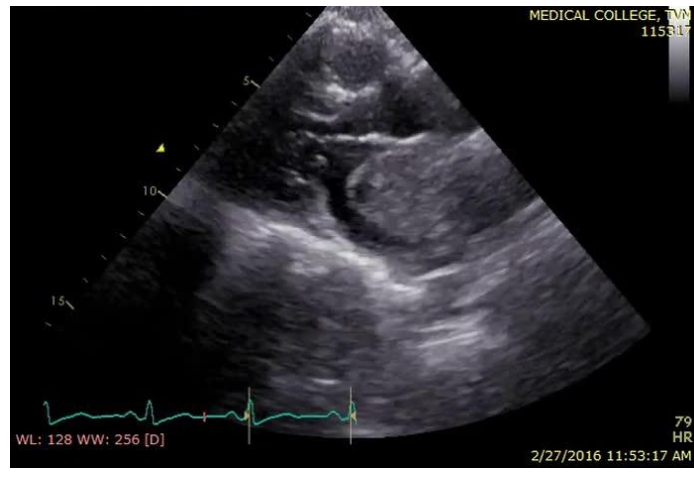

Video 2 Transoesophageal echocardiogram visualising the vegetation within the right atrium with attachment to the interatrial septum. 2D, two dimensional.

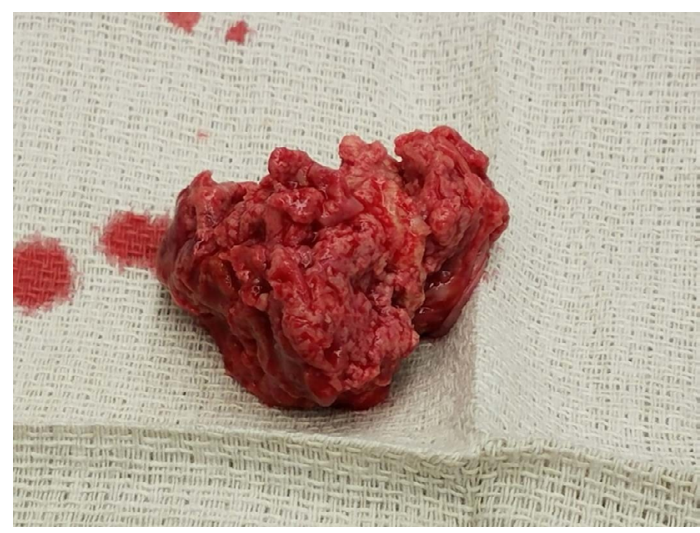

Figure 2 Gross specimen of intracardiac vegetation.

of $56 \%$ with a suspicious right atrial (RA) mass (video 1). It was inconclusive for valvular vegetations, so transoesophageal echocardiogram (TEE) was ordered. Following administration of fluids and broad-spectrum antibiotics, she was transferred to the intensive care unit. Blood cultures were positive for methicillin-sensitive Staphylococcus aureus (MSSA), so the central venous access port was removed.

The patient initially refused a TEE, so it was delayed for 5 days. TEE revealed left ventricular EF of $35 \%-40 \%$ with a large, mobile, heterogeneously echogenic mass visualised encompassing the entire RA cavity with extension into the right ventricle (figure 1 , video 2 ). The mass appeared to be attached to the RA free wall. Cardiothoracic surgery was consulted for emergent mass removal.

During surgery, it was discovered that the mass was densely adherent to the RA wall. After the mass was removed, an intraoperative TEE revealed an EF of 45\%. Gross pathology revealed a 
$5.5 \times 4.0 \times 1.2 \mathrm{~cm}$ tan, focally haemorrhagic, friable, rubbery mass of tissue (figure 2). Microscopic evaluation revealed fibrin with acute inflammation, compatible with vegetation. Her clinical condition gradually improved, and she made a good recovery.

Mural infective endocarditis (IE) occurs when growth of bacteria is present on cardiac walls while valvular endothelium is spared. ${ }^{1}$ Major risk factors for mural IE include diabetes mellitus, cardiovascular disease and malignancy. ${ }^{2}$ Only 19 case reports (20 cases in total) of primary mural IE have been published. ${ }^{2}$ The most common pathogen is $S$. aureus $(60 \%)$. The high virulence of $S$. aureus promotes adherence to endothelium, leading to vegetation formation. ${ }^{2}$ Although the presence of central venous access catheters has been associated with development of IE, mural IE without valvular involvement is extremely rare. ${ }^{3}$ IE diagnosis can be difficult, as TTE images can be inconclusive or non-diagnostic. Consequently, high-resolution TEE imaging is

\section{Learning points}

- Transoesophageal echocardiogram has greater sensitivity for infective endocarditis than transthoracic echocardiogram.

- The index of suspicion for infective endocarditis should be particularly high in patients with sepsis with intracardiac devices.

- Given the high frequency of debilitating and potentially life-threatening complications associated with infective endocarditis, clinicians should be prepared to treat early and aggressively to minimise morbidity. the preferred diagnostic method. ${ }^{12}$ Expedient diagnosis is imperative so treatment may be initiated, as life-threatening complications, such as embolisation, may develop rapidly. ${ }^{2}$ Our case represents a rare instance of isolated mural IE associated with a central venous access port infection. The RA mass observed on TTE in combination with persistent MSSA bacteraemia after central venous access port removal yielded a high index of suspicion for IE. This ultimately led to a TEE, cardiac surgery and a definitive diagnosis.

Contributors YA was the fellow taking care of the patient during the admission discussed in the case. He performed both echocardiograms and was a member of the intervention team. RD was a medical student in the cardiac ICU and took care of the patient during her admission. She prepared the manuscript which was edited and approved by all authors. JD was a medical student in the cardiac ICU and took care of the patient during her admission. MD was the attending interventional cardiologist for this patient during the admission.

Funding The authors have not declared a specific grant for this research from any funding agency in the public, commercial or not-for-profit sectors.

Competing interests None declared.

Patient consent Obtained.

Provenance and peer review Not commissioned; externally peer reviewed.

\section{REFERENCES}

1 Siddiqui WJ, Acharya I, lyer $\mathrm{P}$, et al. Vegetation attached to the left interatrial septal surface at the congenital location of the foramen ovale: a rare occurrence. Am J Case Rep 2016;17:837-40.

2 Tahara M, Nagai T, Takase Y, et al. Primary mural endocarditis without valvular involvement. J Ultrasound Med 2017;36:659-64.

3 Chrissoheris MP, Libertin C, Ali RG, et al. Endocarditis complicating central venous catheter bloodstream infections: a unique form of health care associated endocarditis. Clin Cardiol 2009;32:E48-E54.

Copyright 2018 BMJ Publishing Group. All rights reserved. For permission to reuse any of this content visit

https://www.bmj.com/company/products-services/rights-and-licensing/permissions/

BMJ Case Report Fellows may re-use this article for personal use and teaching without any further permission.

Become a Fellow of BMJ Case Reports today and you can:

- Submit as many cases as you like

- Enjoy fast sympathetic peer review and rapid publication of accepted articles

- Access all the published articles

Re-use any of the published material for personal use and teaching without further permission

For information on Institutional Fellowships contact consortiasales@bmjgroup.com

Visit casereports.bmj.com for more articles like this and to become a Fellow 